\title{
Substrate integrated circuits for high frequency of opto electronics
}

\author{
P. Mounika, R. Yuvaraj \\ Department of Electronics and Communication Engineering, Saveetha Institute of Medical and Technical Sciences, India
}

\begin{tabular}{l}
\hline \hline Article Info \\
\hline Article history: \\
Received May 4, 2020 \\
Revised May 20, 2020 \\
Accepted Jun 7, 2020 \\
\hline
\end{tabular}

\section{Keywords:}

Coordinated

Delineated

Hypothetical

Implementation

Incorporated

\begin{abstract}
Another age of high-recurrence coordinated circuits is displayed, which is called substrate incorporated circuits (SICS). Current cutting edge of circuit plan and implementation stages dependent on this new idea are assessed and dis-cussed in delail. Various potential outcomes and various favorable circumstances of the SICS are appeared for microwave, millimeter-wave and opto hardware applications. Down to earth models are delineated with hypothetical and trial results for substrate coordinated waveguide (SIW), substrate incorporated chunk waveguide (SISW) and substrate incorporated non-transmitting dielectric (SI") direct circuits. Future innovative work patterns are likewise dis-cussed regarding ease imaginative plan of millimeter-wave and optoelectronic coordinated circuits.
\end{abstract}

This is an open access article under the CC BY-SA license.

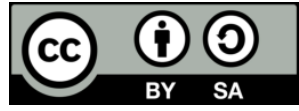

\section{Corresponding Author:}

P. Mounika,

Department of Electronics and Communication Engineering,

Saveetha Institute of Medical and Technical Sciences,

No.162, Poonamallee High Rd, Velappanchavadi, Chennai, Tamil Nadu 600077, India.

Email: mounika.punati07@gmail.com

\section{INTRODUCTION}

Low-cost, mass-producible, elite and high return microwave and millimeter-wave innovations are basic for creating effective advertisement RF broadband frameworks. At millimeter-wave frequencies, specifically, circuit building squares including radio wire components are firmly identified with one another by means of electromagnetic couplings and interconnect. For this situation, the circuit configuration should he made with a worldwide consideration. The old style waveguide innovation is as yet the standard for structuring superior millimeter-wave systems. Be that as it may, this developed plan isn't reasonable for ease large scale manufacturing. Repetitive and costly post-creation tuning and collecting become a genuine issue for manufacturers. Also, the waveguide system would he be able to used to diminish the weight and volume. Then again, testing issues are regularly encountered in the plan of low-misfortune ICs. e.g., high-Q bandpass channel and diplexers, to which the planar strategy is generally restricted in execution. All things considered, non-planar structures, for example, the old style metallic waveguide are normally required, in this manner hybrid plans of planar and, non-planar structures become at-tractive. Truth be told, a simple to deal with ease half and half structure methodology is of basic significance for the advancement of high-volume millimeterwave ICs and frameworks.

Dielectric waveguide has gotten little consideration for microwave and millimeter wave circuit plans despite the fact that it has been contemplated since numerous years. This is on the grounds that it has two central issues, specifically, radiation misfortune due to discontinuity, and troublesome modular progress to planar circuits. The non-emanating dielectric (NRD) waveguide [1] was proposed to determine the greater part of the downsides of dielectric waveguide in con-nection with the radiation misfortune. To take care of 
the issue of mixture planar and non-planar incorporations, we have proposed and created different half and half structure stages that viably consolidate the planar circuits and the non-transmitting dielectric (NRD) waveguide $[2,3]$.

Hence, we have built up the idea of another generation of high-recurrence coordinated circuits called "substrate incorporated circuits - SICs". This new idea has bound together the cross breed and solid reconciliations of different planar and non-planar circuits that are made in single substrate andlor multi-layer stages. In this paper, we will show that the proposed substrate coordinated circuits (SICs) $[4,5]$ engineering can fill in as the structure base for a wide scope of half breed planar/non-planar circuits for millimeter-wave applications. In actuality, the SIC innovation can extraordinarily encourage between associates and mixes among planar and non-planar circuits, which can be made inside a fix creation process. Simultaneously, this plan can be utilized to configuration minimal effort elite (high-Q) inactive circuits, for example, resonators [6], channels [7], couplers [8], power dividers [9], circulators and recieving wires [10].

\section{SUBSTRATE INTEGRATED CIRCUITS}

The key of the SICs idea is to combine non-planar structure with a dielectric substrate and make it in planar structure, which is totally good with other planar structures as shown in Figure 1. This can normally be accomplished by making counterfeit waveguiding channels. For this situation, substituted dielectric conincline profiles of substrate utilizing air openings or composite dielectric media and additionally integrated metallic dividers utilizing metallized vias are by and large sent. The subsequent structure on the substrate will be a planar waveguide, which has much preferred misfortune qualities over planar partners, taking into consideration the structure of millimeter wave high-Q channels, diplexers, resonators and different circuits utilizing an ease creation procedure. Hide thermore, the blend of a non-planar waveguide in substrate allows the acknowledgment of productive wideband changes or baluns between the incorporated non-planar waveguide and planar circuits, for example, microstrip and coplanar waveguide (CPW) coordinated circuits. With these baluns as well as transitions, the intricacy and cost of interconnection between non-planar high-Q circuits and planar circuits are diminished to a base. In this manner, a total millimeter wave front-end circuit for radio and radar applications could be structured and based on one dielectric substrate with just straightforward manufacture process. This makes ready for growing high-recurrence (millimeter-wave) framework on-chip idea if non-direct circuits are additionally incorporated into a similar substrate. This can definitely lessen considerably bundling, interconnect and get together issues that are found in current millimeter wave radio supplies.

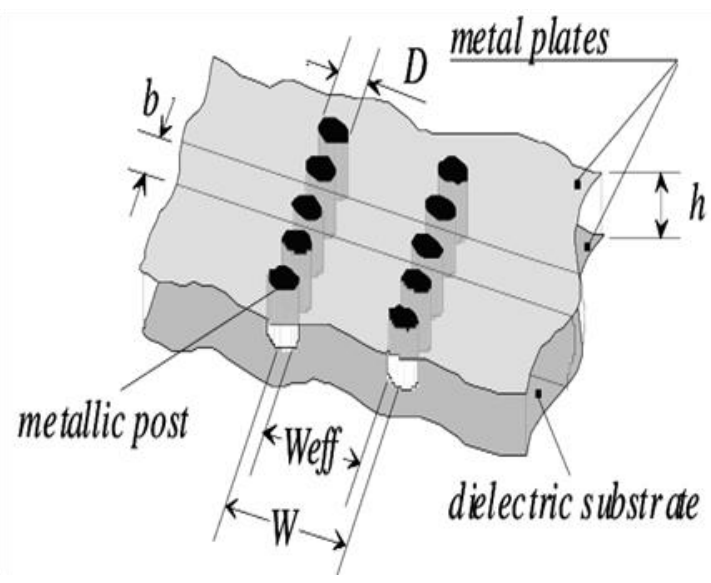

Figure 1. Topology of an SIW guide realized on a dielectric substrate with its physical dimensions

Advances between the SIW and planar circuits, for example, microstrip, CPW or slot line circuits can be based on a similar substrate, as we have examined. For this situation, microstrip and CPW changes are utilized to energize the TElo waveguide mode for the SIW while the slotline progress may effectively energize the TG, waveguide mode. Similar situations can likewise be ap-handled to the SISW and SIINDG. For the SINRD guide, SIIDG and SIIG, the planar circuits are normally created with a con-ventional method on a different substrate that would then be able to be covered onto the SICs. The explanation is that the air openings, which may manage evacuating a great part of the metal part on the SIC substrate, would for 
the most part preclude the creation of planar circuits on a similar substrate except if some complex process is included. For this situation, changes from the SIW to SINRD or SIIDG, which have just been produced for the ordinary structures $[11,12]$, can be sent in a straight-forward way. Regularly, slot line to SW advances would be utilized to finish such interconnect with planar circuits.

\section{SUBSTRATE INTEGRATED WAVEGUIDE (SIW)}

It is known that tlie proposed joining scheines of the conventional rectangular waveguide with planar structures bend hulky and as a rule require an accuracy machining process. which is hard to accomplish at millimeter-wave frequencies for in ass generation. A clear arrangement is to incorporate the rectangular waveguide into microstrip circuit substrate as we have quickly talked about in the above area as shown in Figure 2. This will definitely diminish the Q-factor of waveguide contrasted and the empty rectangular waveguide due to the dielectric filling and volume decrease. The entire circuit including planar circuitry, changes and waveguides can he, in any case, con-structed utilizing standard PCB or other planar handling techniques. Also, the transmission loss of the on-substrate changes might be a lot of lower than that if the advances or coupling areas made between the ordinary waveguide and planar circuits. In this manner. the post width may significantly influence the arrival loss of the waveguide area in perspective on its info port. Two structure rules identified with the post breadth and pitch that are utilized to disregard the radiation misfortune are formulated in [13, 14]. These principles have been deducted from recreation rc-sults of various SIW geometries.
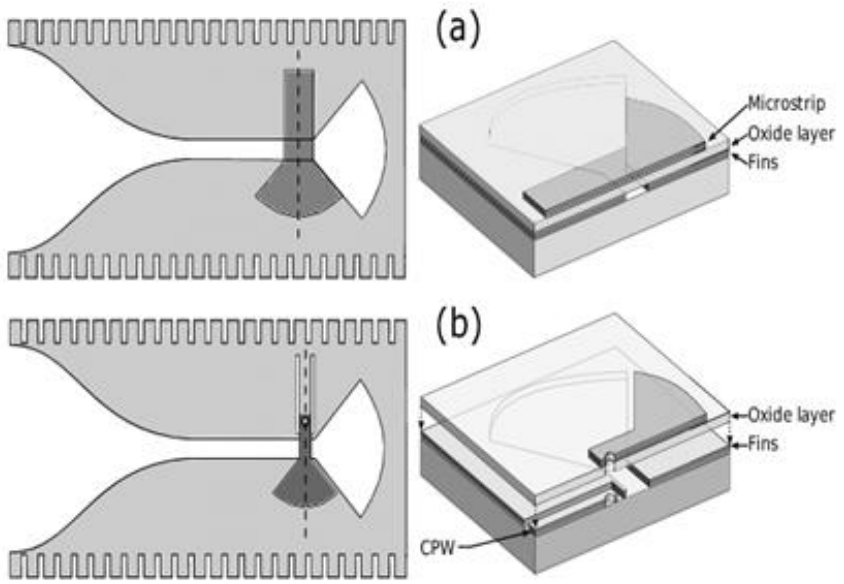

Figure 2. Integrated transitions from planar circuits to SIW guide: (a) Microstrip transition (b) Coplanar waveguide (CPW) transition

\section{SUBSTRATE INTEGRATED SLAB WAVEGUIDE (SISW)}

The section waveguide has been known for its wide bandwidth when planned with a high permittivity dielectric piece. Utilizing 21 dielectric permittivity of 5 for the section two regular rectangular waveguide hands can at the same time he secured with one single piece waveguide. This all-encompassing bandwidth can he valuable to plan recurrence doublers or blender which may require wide transfer speed transmission line.

Usually important to achieve a decent matching. These procedures would expand the cost of the uveidt framework plan. With the SISW strategy the piece manage is blended on a substrate by including air hole into a SIW. Figure 3 delineates the topology if the SISW manage. Utilizing this strategy a SISW covering both $\mathrm{X}$ and $\mathrm{Ku}$ hands has been planned, acknowledged and estimated [15-20].

\section{SURSTRATE INTEGKATED NKD (SINRD) GUIDE}

The NRD-direct is a non-planar structure. what's more, its fundamental geometry comprises of three rectangular dielectric strips: two enormous indistinguishable ones with low dielectric esteem isolated by a little one with a high dielectric esteem. The three strips are sandwiched between two metallic plates with dividing littler than a portion of guided wavelength in the low dielectric locale. It was proposed to smother 
the radiation misfortune inalienable to a dielectric waveguide at its discontinuities. In the SINRD direct an occasional air opening example is utilized to successfully bring down the dielectric consistent of explicit districts of a dielectric substrate, in this manner making a wave-controlling dielectric divert in the substrate. Such an incorporated channel becomes if substrate coordinated NRD guide or SINRD when the top and base of the substrate are shut with metallic planes as shown in Figure 3. Utilizing this method, complex NRD circuits can he worked in one creation step with no manual dealing with. Moreover, the dielectric substrate is adequately strong to permit its overlay with other planar substrate. Along these lines, the half breed planar NRD control systems can be niade tiiore cost-viably and effectively.

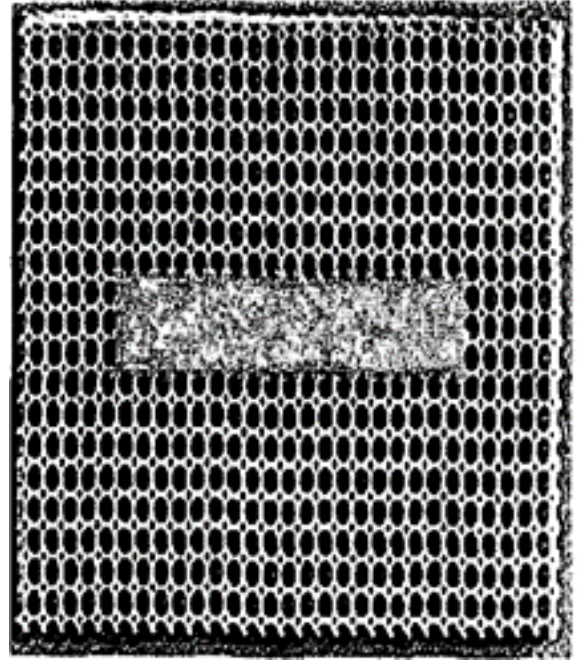

(a)

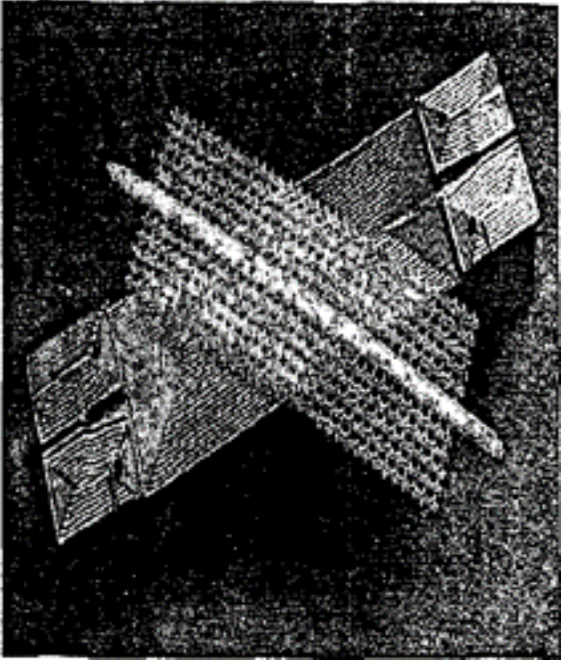

(b)

Figure 3. Surstrate Integkated, (a) A machined Cuflon SINRD circuit at $36 \mathrm{GHz}$ which is laminated to a RT6002 $0.254 \mathrm{~mm}$ thick substrate on which the microstrip-to-SINKD transitions are etched, (b) SINRD circuit on Cuflon working at $80 \mathrm{GHz}$ with WRIO transitions.

\section{SUBSTRATE INTEGRATED IMAGE DIELECTRIC GUIDE (SIIDG)}

The SIC procedure was likewise utilized in the trial proto-kind of a dielectric resonator radio wire exhibit [10], every receiving wire being in reality a SIIDG resonator. The SIC points of interest in this millimeter-wave receiving wire are precisely vigorous in light of the fact that the entirety of the little resonator components are made of and fixed on the dielectric substrate, consequently lessening impressively the adjustment issue of the resonators. Moreover, the receiving wire exhibit exhibitions were demonstrated to be equivalent or superior to those of the regular acknowledgment strategy. Some electrical features, for example, gain control could undoubtedly be accomplished by changing the air gap design measurements.

\section{CONCLUSION}

This paper exhibits a diagram of the present substrate integrated circuits (SICS) improvement with various practical models. Specialized highlights of this new age of microwave incorporated circuits are shown with configuration rules and circuit execution. Mechanical and electrical properties are talked about in detail concerning different SIC platforms. Future patterns are additionally shown with accentuation on the advancement of future minimal effort and superior millimetre wave, submillimeter-wave and optoelectronic applications. It is accepted this new idea will in a general sense change the scene of our high-recurrence research and development. Affirmation The creators might want to offer their thanks to the NSERC of Canada and NQRNT of Quebec for their money related backings that have made this work conceivable. The creators would likewise say thanks to Steve Dub6 for his assistance in the manufacture of the models.

\section{ACKNOWLEDGEMENTS}

The authors would like to thank to the NSERC of Canada and NQRNT of Quebec for their money related backings that have made this work conceivable. The creators would likewise express gratitude toward Steve Dub6 for his assistance in the manufacture of the models. 


\section{REFERENCES}

[1] T. Yoneyama and S. Nishida, "Nonradiative dielectric waveguide for millimeter wave integrated circuits," IEEE Trans. MicrowaveTheoryTec., vol. 29, pp.1188-1192. Nov. 1981.

[2] K. Wu. L. Han, "Hybrid integration technology of planar circuits and NRD-guide for cost-effective microwave and millime- ter-wave applications," IEEE Trans. Microwave Theory and Tech., vol.45, no. 6, pp.946-954, Jun 1997.

[3] K. Wu, Y. Cassivi, "Recent advances of hybrid planarINRD- guide technology for millimeter-wave integrated circuit design," 5th International Conference on Telecommunications in Modern Satellite, Cable and Broadcasting Service. TELSIKS 2001. Proceedings of Papers (Cat. No. 01EX517), vol. 1, pp. 187-193, 2001.

[4] K. Wu, "Integration and interconnect techniques of planar and non-planar structures far microwave and millimeter-wave circuits-current status and future trend," Proceeding of Asia-Pacific Microwave Conference, pp. 411-416, 2001.

[5] K. Wu and F. Boone, "Guided-wave properties of synthesized non-radiating dielectric waveguide for substrate integrated circuits (SICS)," 2001 IEEE MIT-S Inter. Microwave Symp., Phcinix. USA, pp. 723.726, 2001.

[6] Y. Cassivi, L. Perregrini, K. Wu and G. Conciauro, "Low-cost and high-Q millimeter-wave resonator using substrate inte-grated waveguide technique," 2002 32nd European Microwave Conference, Nov. 2002

[7] D. Deslandes and K. Wu, "Single-substrate integration tech- niques for planar circuits and waveguide filters," IEEE Trans- actions on Microwave Theory and Techniques, vol. 51, no. 2, pp. 593-596, Feb. 2003.

[8] Y. Cassivi. D. Deslandes and K. Wu, "Substrate integrated waveguide directional couplers," in Asia-Pacific microwave conference, Kyoto, Japan, pp. 1409-1412, Nov 2002.

[9] S. Germain, D. Deslandes, K. Wu, "Development of substrate integrated waveguide power dividers," CCECE 2003-Canadian Conference on Electrical and Computer Engineering. Toward a Caring and Humane Technology (Cat. No. 03CH37436), vol. 3, pp. 1921-1924, May 2003.

[10] A. Petosa. A. lttipiboon and S. Thirakoune, "Perforated dielec- tric resonator antennas," Electronics Letters, vol. 38, No. 24, pp. 1493-1495, 2002

[11] Y. Cassivi and K. Wu, "Compact transition from non-radiating dielectric (NRD) to rectangular waveguides," IEEE Microwave and Wireless Component Letters, submitted for publication, 2003.

[12] T. Rozzi and S. 1. Hedges. "Rigorous analysis and network modeling of the inset dielectric guide," IEEE Transactions on Microwave Theory and Techniques, vol. 35, no. 9, pp. 823-834, Sept. 1987.

[13] H.-J. J. Yeh, and J. S. Smith, "Fluidic self-assembly for the integration of GaAs light-emitting diodes on Si substrates," IEEE Photon. Technol. Lett., vol. 6, no 6, pp. 706-708, Jun 1994.

[14] J. K. Tu, J. J. Talghader, M. A. Hadley, and J. S. Smith, "Fluidic self-assembly of InGaAs vertical-cavity surfaceemitting lasers onto Silicon," Electron. Lett., vol. 31, pp. 1448-1449, Aug. 1995.

[15] D. Deslandes and K. Wu, "Design Considerations and Perform- ance Analysis of Substrate Integrated Waveguide Components," Milano, European Microwave Conference, pp. 881-884, Sep 2002.

[16] D. Deslandes, M. Bozzi. P. Arcioni and K. Wu, "Substrate Inte- grated Slab Waveguide (SISW) for ,Wideband Microwave Ap- plications," IEEE Int. Microwave Symp, Philadelphia, PA, USA, pp. 1975-1978, 2003.

[17] H. Wada, T. Takamori, and T. Kamijoh, "Room temperature photopumped operation of $1.58 \mathrm{~m}$ vertical-cavity lasers fabricated on Si substrates using wafer bonding," IEEE Photon. Technol. Lett., vol. 8, pp. 181-198, 1997.

[18] N. M. Margalit, D. I. Babic, K. Streubel, R. P. Mirin, R. L. Naone, J. E. Bowers, and E. L. Hu, "Submilliamp longwavelength vertical cavity lasers," Electron. Lett., vol. 32, pp. 1675-1677, Aug. 1996.

[19] Z. H. Zhu, F. E. Ejeckam, Y. Qian, J. Zhang, G. L. Christenson, and Y. H. Lo, "Wafer-bonding technology and its applications in optoelectronic devices and materials," IEEE J. Select. Topics Quantum Electron., vol. 3, no. 3, pp. 927-936, 1997.

[20] S. Matsuo, K. Tateno, T. Nakahara, H. Tsuda, and T. Kurokawa, "Use of polyimide bonding for hybrid integration of a vertical cavity surface emitting laser on a silicon substrate," Electronics Letters., vol. 33, no. 3, pp. 1148-1149, 1997. 